\title{
Oil Palm Trunk of Elaeis guineensis as a Major Source of Commercial Lignocellulosic Materials: A Short Review
}

ISSN: 2637-7659

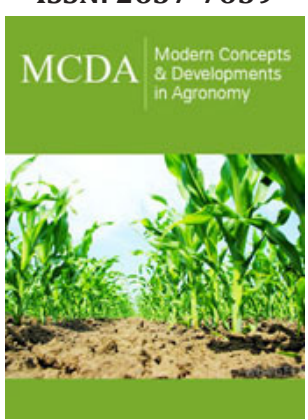

*Corresponding author: Chee Kong Yap, Department of Biology, Faculty of Science, Universiti Putra Malaysia, 43400 UPM Serdang, Selangor, Malaysia

Submission: 睯July 31, 2021

Published: 侮 August 25, 2021

Volume 9 - Issue 3

How to cite this article: Chee Kong Yap, Wen Siang Tan, Shih Hao Tony Peng, et al. Oil Palm Trunk of Elaeis guineensis as a Major Source of Commercial Lignocellulosic Materials: A Short Review. Mod Concep Dev Agrono. 9(3). MCDA. 000711. 2021. DOI: 10.31031/MCDA.2021.09.000711

Copyright@ Chee Kong Yap. This article is distributed under the terms of the Creative Commons Attribution 4.0 International License, which permits unrestricted use and redistribution provided that the original author and source are credited.
Chee Kong Yap ${ }^{1 *}$, Wen Siang Tan ${ }^{2,3}$, Shih Hao Tony Peng 4 , Wan Hee Cheng ${ }^{5}$, Mohd Hafiz Ibrahim ${ }^{1}$, Uma Rani Sinniah ${ }^{6}$, Rosimah Nulit ${ }^{1}$, Chee Wah Yap $^{7}$ and Mohamad Saupi Ismail ${ }^{8}$

${ }^{1}$ Department of Biology, Faculty of Science, Universiti Putra Malaysia, 43400 UPM Serdang, Selangor, Malaysia

${ }^{2}$ Department of Microbiology, Faculty of Biotechnology and Biomolecular Sciences, Universiti Putra Malaysia, 43400 UPM Serdang, Selangor, Malaysia

${ }^{3}$ Laboratory of Vaccines and Biomolecules, Institute of Bioscience, Universiti Putra Malaysia, 43400 UPM Serdang, Selangor, Malaysia

${ }^{4}$ All Cosmos Bio-Tech Holding Corporation, PL0650, Jalan Keluli, Pasir Gudang Industrial Estate, 81700 Pasir Gudang, Johor, Malaysia

${ }^{5}$ Inti International University, Persiaran Perdana BBN, 71800 Nilai, Negeri Sembilan, Malaysia

${ }^{6}$ Faculty of Agriculture Universiti Putra Malaysia, 43400 UPM Serdang, Selangor, Malaysia

${ }^{7}$ MES SOLUTIONS, 22C-1, Jalan BK 5A/2A, Bandar Kinrara, 47100 Puchong, Selangor, Malaysia

${ }^{8}$ Fisheries Research Institute, Batu Maung, 11960 Pulau Pinang, Malaysia

\section{Abstract}

The goal of this paper was to review the uses of oil palm trunk (OPT) as a source of lignocellulosic materials (LM), and to discuss its future prospects. The present review focuses on three points; first, large quantity of OPT; second, many studies reported the commercial use of OPT and third, many studies reported the conversion methods of OPT into LM sources. Most of the studies revealed that OPT can be transformed readily into biomaterials for value-added products The LM from OPT have many potential industrial applications.

Keywords: Oil palm trunks; lignocellulosic materials; industrial application.

\section{Introduction}

Oil palm (OP) (Elaeis guineensis Jacq.) is a valuable crop commodity that has expedited the progress of the agricultural sector in Malaysia. Apart from the OP products, the oil palm biomass (OPB) is also produced abundantly in plantations. This OPB includes oil palm empty fruit bunch (OPEFB), oil palm fronds (OPF), and oil palm trunk (OPT) [1]. Recently, Yap et al. [2] reviewed the potentials and challenges of using renewable oil palm biomass wastes (OPBW) in Malaysia including the OPT.

The purpose of this paper was to review the uses of OPT as a source of LM, and to discuss its future applications. OPT is the main subject of this review article, which is discussed comprehensively based on the following three major points.

\section{First, large quantity of oil palm trunk}

According to Abdullah et al. [3], the OPT is normally left at planted locations to be decomposed naturally. Because of the low decomposition rate, the lack of correct management 
of this OPBW will disrupt the OP plantation's regular growth process. Furthermore, it has the potential to stimulate the spread of OP disease caused by Ganoderma boninense, which is harmful to the OP crop.

Despite the large amount of OP produced, the oil only accounts for a small fraction of the total biomass produced in OP plantations while the remainder consisting of lignocellulosic materials (LM) such as OPT [4]. Even though the OPBW are classified as organic wastes that can be degraded naturally. Nonetheless, huge amounts of these wastes can potentially harm the OP plantation environment.

The OPT is a solid trash that is produced in great amounts once OP trees are felled, and it is available all the year round. OPT lumber, OPT chips, and OPT fibers are the three types of OPT [5]. Because of the wide range of physical and mechanical qualities, scientists and manufacturers have difficulties using these solid wastes for various applications. The solid wastes of OPT have a higher commercial potential than the other varieties of OPBW. OPT's cellulosic material is used to make value-added products since it is made up of LM [6]. Sulphuric acid hydrolysis was used to study the possibility of manufacturing glucose from OP lignocellulosic wastes such as OPT, OPF, and OPEFB. The glucose was then fermented with the Saccharomyces cerevisiae yeast [7].

\section{Second, many studies reported the commercial use of oil palm trunk}

Lignocellulosic materials (LM) are the dry matters of plants. They are composed of aromatic polymers like lignin and carbohydrate polymers (cellulose and hemicellulose). Different sugar monomers (six and five carbon sugars) are strongly linked to the aromatic polymer in carbohydrate polymers [8]. Because of their low cost and abundance, LM are the best feedstocks [9]. These lignocellulosic compounds have huge potential in food, chemical, and pharmaceutical industries [10]. The OPT, like OPEFB, has a stronger commercial potential than the other forms of OPBW [11]. As a result, the OPT, which makes up the majority of lignocellulosic waste, is now available for commercial use. However, in order for OP producers across the world, such as Malaysia and Indonesia, to keep their competitive edge, a zero-waste policy must be implemented [12].

Previous research has demonstrated that biomass and other agricultural waste may be utilized to manufacture a number of high-value items, such as medium-density panels, chip boards, thermoset composites and thermoplastics, nano biocomposite, pulp and paper [13]. The OPT houses the majority of LMs that can be used for commercial purposes. Lamaminga et al. [14] examined the cellulose nanocrystals extracted from OPT and recommended it as a value-added product [12].

According to Sumanthi et al. [15], an OP tree produces $231.5 \mathrm{~kg}$ dry weight of biomass per year, which includes oil and lignocellulosic components. Oil palm agriculture produces a large amount of lignocellulosic biomass, including OPT, from OPB. Only a little percentage is used for fibre production and energy generating. About $40 \%$ of the biomass is cellulose, $40 \%$ is hemicellulose, $18 \%$ is lignin, and 2\% is extractives [4]. The OPT, for instance, has 34.4, $23,9,35.9 \%$ of cellulose, hemicellulose and lignin, respectively [16].

OPT solid wastes have a higher commercial potential than other types of OPBW [11]. The high proportion of cellulose and hemicellulose in the OPF, OPT and EPB suggests that the OPB could be employed as a bioprocessing feedstock [17]. Laminated bio-composite and hybrid laminated bio-composite with good characteristics have been successfully manufactured using OPT and OPT reinforced with EFB [3].

Mazlan et al. [18] proposed that lignocellulosic OPT biomass might be used as an alternate substrate for enzymatic saccharification of glucose. Prior to the enzymatic saccharification procedure for glucose production, the OPT biomass was pretreated using a steam-alkali-chemical technique. The researchers discovered that by employing treated OPT as a substrate improved the enzyme digestibility.

Using two different ionic solutions, Mohd Basyaruddin et al. [19] investigated the swelling and dissolving of OPB and cellulose fibre from OPEFB, OPF, and OPT. Mohtar et al. [20] extracted lignin from OPB, namely OPEFB, OPT and OPF, using an ionic liquid solution followed by precipitation with various precipitating agents such as CO2-AlK (SO4)2·12H2O precipitation. The chemical and lignin contents of OPT samples from two genetic origins were studied by Ho et al. [21]. The two OP genotypes' structural carbohydrate and lignin compositions were found to differ considerably.

\section{Third, many studies reported the conversion methods of OPT into LM sources}

Mazlita et al. [22] claimed to have effectively developed chemical-sonication processes from OPT lignocellulosic biomass. Noorshamsiana et al. [10] conducted a review of the conversion of OPT into lignocellulosic compounds, focusing on several extraction procedures and discussing their advantages and disadvantages.

According to Eom et al. [23], fermentation of the sap, bagasse, or cell wall can efficiently convert solid lignocellulosic OPT to ethanol. Hydrothermal treatment of cellulose, hemicellulose and lignin in OPT's cell wall, followed by enzymatic hydrolysis, can yield the required bio-products [23]. Kosugi et al. [24] reported the production of ethanol and lactic acid by using sap squeezed from old OPT. They found that sugars (glucose, sucrose, and fructose) were present in the sap of the OPT tree [24]. Vitamins, amino acids, and organic acids are among the other chemical substances found in OPT sap. As a result, the sap from the OPT tree can be immediately fermented to yield chemical compounds such lactic acid and ethanol [25-27].

\section{Conclusion}

This review article focuses on three main points: large quantity of OPT, many studies reported the commercial uses of OPT, many studies reported the conversion methods of OPT into LM sources. All the literature reviews pointed toward the potentials of OPT to be transformed into biomaterials for value-added products for industrial applications in the future. 


\section{References}

1. Awalludin MF, Othman S, Rokiah H, Wan NA, Wan N (2015) An overview of the oil palm industry in Malaysia and its waste utilization through thermochemical conversion, specifically via liquefaction. Renew Sustain Energy Rev 50: 1469-1484.

2. Yap CK, Yap CW, Tony Peng SH, Sinniah UR, Leow CS, et al. (2019) Oil palm biomass wastes as renewable energy sources in Malaysia: Potentials and challenges. Glob J Civil Environ Eng 1: 20-24.

3. Abdullah N, Sulaiman F (2013) The oil palm wastes in malaysia, biomass now - sustainable growth and use, Miodrag Darko Matovic, Intech Open.

4. Mohd Azemi, Mohd N, Harun S (2000) Oil palm (Elaeis guineensis) wastes as a potential source of cellulose. Cellulosic Pulps, Fibres and Materials. Cellucon '98 Proceedings 2000: 13-17.

5. Dungani R, Aditiawati P, Aprilia S, Yuniarti K, Karliati T, et al. (2018) Biomaterial from oil palm waste: Properties, Characterization and Applications. Intech Open.

6. Dungani R, Jawaid M, Khalil HPSA, Jasni J, Aprilia S, et al. (2013) A review on quality enhancement of oil palm trunk waste by resin impregnation: Future materials. Bio Resources 8(2): 3136-3156.

7. Yeoh HH, Lim KO (2000) Production of fuel ethanol from oil palm wastes. Int Energ J 1(2): 89-95.

8. Den W, Sharma VK, Lee M, Nadadur G, Varma RS (2018) Lignocellulosic biomass transformations via greener oxidative pretreatment processes: Access to energy and value-added chemicals. Front Chem 6: 141.

9. Balat M (2011) Production of bioethanol from lignocellulosic materials via the biochemical pathway: A review. Energy Conv Manage 52(2): 858875.

10. Noorshamsiana AW, Nur Eliyanti AO, Fatiha I, Astimar AA (2017) A review on extraction processes of lignocellulosic chemicals from oil palm biomass. J Oil Palm Res 29(4): 512-527.

11. Yuliansyah AT, Hirajima T, Rochmadi R (2009) Development of the Indonesian palm oil industry and utilization of solid waste. J Mining Mater Proc Inst Japan 125(12): 583-589.

12. Rafidah J, Asma W, Puad E, Mahanim SMA, Shaharuddin H (2012) Toward zero waste production of value-added products from waste oil palm trunk (WOPT). In: Proceedings of $8^{\text {th }}$ Biomass Asia Workshop, Hanoi-Vietnam, pp. 25-46.

13. Abdul Khalil HPS, Bhat AH, Ireana Yusra AF (2011) Green composites from sustainable cellulose nanofibrils: A review. J Carbohydrate Poly 87: 963-979.

14. Lamaminga J, Hashim R, Sulaimana O, Leh CP, Sugimoto T, et al. (2015) Cellulose nanocrystals isolated from oil palm trunk. Carbohydrate Polymers 127: 202-208.
15. Sumanthi S, Chai SP, Mohamed AR (2008) Utilization of oil palm as a source of renewable energy in Malaysia. Renew Sustain. Energy Rev 12(9): 2404-2421.

16. Onoja E, Chandren S, Abdul Razak FI, Mahat NA, Abdul Wahab R (2018) Oil palm (Elaeis guineensis) biomass in Malaysia: The present and future prospects. Waste and Biomass Valorization 10: 2099-2117.

17. Loh SK (2016) The potential of the Malaysian oil palm biomass as a renewable energy source. Energy Convers Manag 141: 285-298.

18. Mazlan NW, Lai LW, Suliman NK, Ibrahim M, Taib RM, et al. (2017) Glucose production from steam-alkali-chemical pre-treated oil palm trunk biomass via enzymatic saccharification process. Malaysian Journal of Analytical Sciences 21(2): 283-290.

19. Mohd Basyaruddin AR, Zati II, Dzulkefly KA, Astimar AA, Mahiran B, et al. (2012) Swelling and dissolution of oil palm biomass in ionic liquids. J Oil Palm Res 24: 1267-1276.

20. Mohtar SS, Tengku Malim Busu TNZ, Md Noor AM, Shaari N, Yusoff NA, et al. (2015) Extraction and characterization of lignin from oil palm biomass via ionic liquid dissolution and non-toxic aluminium potassium sulfate dodecahydrate precipitation processes. Bioresour Technol 192: 212-218.

21. Ho LS, Tan BA, Md Noh NA, Talib SS, Ithnin N, et al. (2015) Preliminary analysis of lignocellulose content and monolignol composition of oil palm trunk from two different genetic backgrounds. Bio Res10(4): 8194-8207.

22. Mazlita Y, Lee HV, Hamid SBA (2016) Preparation of cellulose nanocrystals bio-polymer from agro-industrial wastes: Separation and characterization. Poly Polymer Composites 24(9): 719-728.

23. Eom IY, Yu JH, Jung CD, Hong KS (2015) Efficient ethanol production from dried oil palm trunk treated by hydrothermolysis and subsequent enzymatic hydrolysis. Biotechnol Biofuels 8: 83.

24. Kosugi A, Tanaka R, Magara K, Murata Y, Arai T, et al. (2010) Ethanol and lactic acid production using sap squeezed from old oil palm trunks felled for replanting. J Biosci Bioeng 110(3): 322-325.

25. Komonkiat I, Cheirsilp B (2013) Felled oil palm trunk as a renewable source for biobutanol production by Clostridium spp. Bioresour Technol 146: 200-207.

26. Shahirah MNN, Gimbun J, Pang SF, Zakria RM, Cheng CK, et al. (2014) Influence of nutrient addition on the bioethanol yield from oil palm trunk sap fermented by Saccharomyces cerevisiae. J Ind Eng Chem 23: 213-217.

27. Bakar ES, Rachman O, Hermawan D, Karlinasari L, Rosdiana N (1998) Utilization of oil palm trunk (Elaeis guineensis Jacq) as construction materials and furniture (I): Physical, chemical and natural durability properties of oil palm wood. Journal of Forest Products Technology 11(1): 1-11. 